\title{
Systematic review and meta-analysis of the effect of using percutaneous pedicle screw internal fixation for thoracolumbar fractures
}

\author{
Jiong Lu, Yinan Chen, Minwei Hu, Changhui Sun \\ Department of Orthopedic, Affiliated Ruijin Hospital Luwan Branch, Shanghai Jiao Tong University School of Medicine, Shanghai, China \\ Contributions: (I) Conception and design: J Lu, C Sun; (II) Administrative support: Y Chen; (III) Provision of study materials and patients: J Lu, Y \\ Chen, M Hu; (IV) Collection and assembly of data: All authors; (V) Data analysis and interpretation: J Lu, M Hu, C Sun; (VI) Manuscript writing: \\ All authors; (VII) Final approval of manuscript: All authors. \\ Correspondence to: Changhui Sun. Department of Orthopedic, Affiliated Ruijin Hospital Luwan Branch, Shanghai Jiaotong University School of \\ Medicine, No. 149 Chongqing South Road, Huangpu District, Shanghai 200020, China. Email: sunchanghui189@163.com.
}

\begin{abstract}
Background: Thoracolumbar fractures are common in routine injuries. The best way to treat a thoracolumbar fracture is to repair the thoracic fracture with fixation, which is classified into percutaneous pedicle screw fixation and open pedicle screw fixation.

Methods: The literature was searched in the English database PubMed, Ovid-Medline, Embase, and China Biology Medicine Disc (CBM) from the date of establishment of PubMed to June 2021, and keywords such as percutaneous pedicle screw and posterior percutaneous pedicle screw fixation were searched. A metaanalysis was performed using RevMan5.3, which was provided by Cochrane.com.

Results: A total of 9 articles were included. The results showed that the operative time of percutaneous pedicle screw fixation was shorter than that of open pedicle screw fixation. Percutaneous pedicle screw internal fixation had better Cobb angle restoration effect than open pedicle screw internal fixation. However, there were considerable differences in pain and screw misplacement rates. In addition, the pain after percutaneous pedicle screw fixation was smaller than that after open pedicle screw fixation, and patients had better compliance.
\end{abstract}

Discussion: Compared with open surgery, percutaneous pedicle screw fixation had a shorter operation time, better cobb angle recovery, and a lower pain sensation following surgery. The low rate of screw misplacement and postoperative infection suggested that percutaneous pedicle screw fixation was more effective than open surgery.

Keywords: Percutaneous pedicle screw fixation; open pedicle screw internal fixation; thoracic vertebral fractures; meta-analysis

Submitted Nov 25, 2021. Accepted for publication Jan 11, 2022.

doi: 10.21037/apm-21-3736

View this article at: https://dx.doi.org/10.21037/apm-21-3736

\section{Introduction}

A thoracolumbar fracture is one of the most common spinal fractures. A thoracolumbar fracture may affect the central nervous system and the lungs and therefore must be taken seriously $(1,2)$. Thoracolumbar fractures are common fractures because the thoracolumbar segment is the concentration point of spinal stress, therefore it has the highest incidence of spinal fractures (3). The presence of the spinal cord and nerves in the spinal canal that are composed of thoracolumbar vertebral fractures mean that severe vertebral fractures can also be complicated by spinal cord or nerve injury. In the case of a burst fracture of the cervical vertebra, the patient may die instantly from asphyxiation because this can affect the respiratory center (4). 
Currently, an anterior approach, a posterior approach, a combined anterior and posterior approach, and minimally invasive surgery are widely used for the treatment of thoracolumbar fractures (5). In clinical practice, posterior access to traditional open pedicle screw surgery and percutaneous pedicle screw surgery are the most common treatments (6). The choice of surgical procedure should be based on the patient's fracture type, neurological dysfunction, damaged spinal stability, and the surgeon's clinical skill level (7). Different surgical methods have their own advantages and disadvantages; therefore, the overall situation of patients should be fully taken into consideration when surgical methods are selected (8). Currently, posterior pedicle screw fixation is the most widely used method in clinical practice. Numerous clinical studies have shown that this method can immediately restore normal spinal sequence reconstruction and maintain spinal stability (9). However, this traditional surgical method also has significant disadvantages such as the method for patients with traumatic big, long operation time, intraoperative blood loss, and longer duration of postoperative pain in patients with incision, generally required long-term postoperative incision drainage tube, leading to stay in bed longer hospitalization and recovery. For a long time how to reduce the rate of posterior pedicle screw internal fixation surgery of iatrogenic injury has always been the focus of the orthopedic surgeon. In recent years, with the continuous development of minimally invasive surgery, percutaneous pedicle screw fixation advantages gradually revealed. A large number of clinical data showed that the percutaneous pedicle screw internal fixation surgery without to reset satisfaction, keep the advantages of the fixation strength, but also reduce the damage to the lumbar posterior structure, with simple operation small trauma hemorrhage less operation time is short (10). At present, there are very few studies comparing the efficacy of traditional and percutaneous pedicle screw internal fixation in the treatment of thoracolumbar vertebral fractures in terms of the evaluation of the efficacy of percutaneous pedicle screw internal fixation in the treatment of thoracolumbar vertebral fractures, such as the amount of intraoperative blood loss and postoperative drainage flow and postoperative pain (11).

In this paper, existing randomized trials were collected and systematically analyzed to compare the efficacy of traditional methods and percutaneous pedicle screw fixation in order to provide comprehensive quantitative indicators and provide evidence basis for subsequent clinical treatment. We present the following article in accordance with the PRISMA reporting checklist (available at https://apm.amegroups.com/ article/view/10.21037/apm-21-3736/rc).

\section{Methods}

\section{Literature search strategy}

At present, the literatures on percutaneous pedicle screw fixation are mostly in English, and there are very few Chinese literatures. Therefore, the search scope of this paper is PubMed, Ovid-Medline, Embase, and China Biology Medicine Disc (CBM). The search time was from the establishment of the database to June 2021. Percutaneous pedicle screw, posterior percutaneous pedicle screw fixation, open pedicle screw fixation, fracture of thoracic vertebrae, thoracic fractures, thoracic, and vertebral fracture were set as keywords. Literatures were screened according to the following inclusion and exclusion criteria.

\section{Literature inclusion and exclusion criteria}

A study was included if it fulfilled the following criteria: (I) the study had sufficient experimental data and contained the required basic information including data of various indicators related to the study (operative time, Cobb angle recovery, postoperative pain, and postoperative screw dislocation rate); (II) the disease being studied was a thoracolumbar vertebral fracture; (III) the study had a sufficient number of cases, with a large enough sample (research sample $\geq 10$ ); and (IV) the study was a clinical trial. Unpublished works that fulfilled these criteria were also included.

A study was excluded if it satisfied one of the following criteria: (I) the study was non-Chinese literature; (II) the study was a meta-analysis; (III) the study was not a clinical trial; (IV) there was no control group; and/or (V) the study had incomplete recording of basic patient data.

\section{Literature screening}

Independent literature screening and data extraction were implemented by two experts, and cross-checking was also performed. If there were different opinions, experts in this hospital who have been engaged in relevant clinical work for more than five years were consulted to decide on the final data selection.

\section{Data extraction}

The observation indexes included postoperative pain, operation time, postoperative infection rate, and screw 
dislocation rate. A visual analogue scale (VAS) was used to evaluate the postoperative pain of minimally invasive percutaneous pedicle screws and traditional open pedicle screws. Postoperative complications of minimally invasive percutaneous pedicle screws and traditional open pedicle screws mainly included the screw dislocation rate and infection rate. Imaging parameters included the Cobb angle of the surgical segment after minimally invasive percutaneous pedicle screws and conventional open pedicle screws. When accurate means and standard deviations were not reported in the included literature, estimates were made from the charts used in the literature. All data were sourced from the included articles. Two reviewers independently reviewed the literature and assessed the quality of each article. When there were differences of opinion, the problem was solved through discussion or the intervention of the third-party reviewer.

\section{Quality assessment}

To improve the quality of the reviewed literature, a quality assessment was carried out according to the "Risk assessment of bias" recommended in version 5.3 of the Cochrane System's review manual. The evaluation included the following seven items: (I) which random method was used; (II) whether there was a hidden allocation; (III) blind implementation of patients and researchers; (IV) whether the effect of the blind method was assessed; (V) whether there was integrity of the results; (VI) whether the investigation results were credible; and (VII) other bias. As for the seven items of each randomized controlled trial (RCT), "satisfied" meant the study contained a relatively small degree of bias, while "unsatisfied" meant the study contained a high degree of bias. That is, if the literature is in the confidence interval and symmetric, there is no publication deviation; otherwise, there is deviation. If studies were not sufficiently detailed to report, or it was not mentioned, the risks were unknown. The evaluation of existing studies included four dimensions, which were: (I) random sequence generation; (II) allocation hiding; (III) blinding; and (IV) racking/exit. For each of these dimensions, studies with scores of 1-3 were considered low quality, and studies with scores of 4-7 were considered high quality.

\section{Statistical methods}

RevMan5.3.5 (Cochrane, London, UK) was used for data analysis. Dichotomous variables were evaluated by relative risk (RR) and odds ratio (OR). The weighted mean difference (WMD) was used to evaluate the continuity variable and calculate its $95 \%$ confidence interval (CI). For heterogeneity of literature, homogeneity of the included studies was tested by $\chi^{2}$ test. If $\mathrm{P}>0.1$ and $\mathrm{I}^{2}<50 \%$, the included literatures were considered homogenous or consistent, and the fixed-effect model was adopted. If $\mathrm{P}<0.1$ and $\mathrm{I}^{2}>50 \%$, heterogeneity was considered in the included literature data, and the random effect model was used for analysis. The level of meta-analysis was set as $\alpha=0.05$, and $\mathrm{P} \leq 0.05$ was considered statistically significant.

\section{Results}

\section{Search results}

In total, 570 articles were retrieved from the database, and 732 articles from the registers. After the title of all papers were read, 566 articles that did not meet the inclusion criteria were excluded. After the abstract of all papers were read, 77 articles that did not meet the inclusion criteria were excluded. After the full text was read, 625 articles were excluded. Finally, 25 article which did not meet the requirements were excluded, and 9 articles (12-20) that met the inclusion criteria were included in the meta-analysis. The document screening flowchart is shown in Figure 1. Basic information included in the study is shown in Table 1.

\section{Risk bias evaluation of literatures}

The Cochrane Handbook version 5.3 systematic review writing manual was adopted to evaluate the bias risk of the 9 documents included in this study and to construct the bias risk chart. Figures 2,3 show the details of this process. Review Manager 5.3 (Nordic Cochrane Center) was used to express the results.

\section{Operation time}

A total of 8 documents met the requirements and used percutaneous pedicle screws and posterior percutaneous pedicle screw internal fixation. The results in Figure 4 show that the $95 \%$ CI was $-0.27(-0.90,0.35)$ and $\mathrm{I}^{2}=86 \%$, which was greater than $50 \%$, so the random effects model was selected. The results showed that the operation time for percutaneous pedicle screw fixation was shorter than that of open pedicle screw fixation, but the difference was not significant $(\mathrm{Z}=0.85 ; \mathrm{P}=0.40)$. Figure 5 shows that most of 


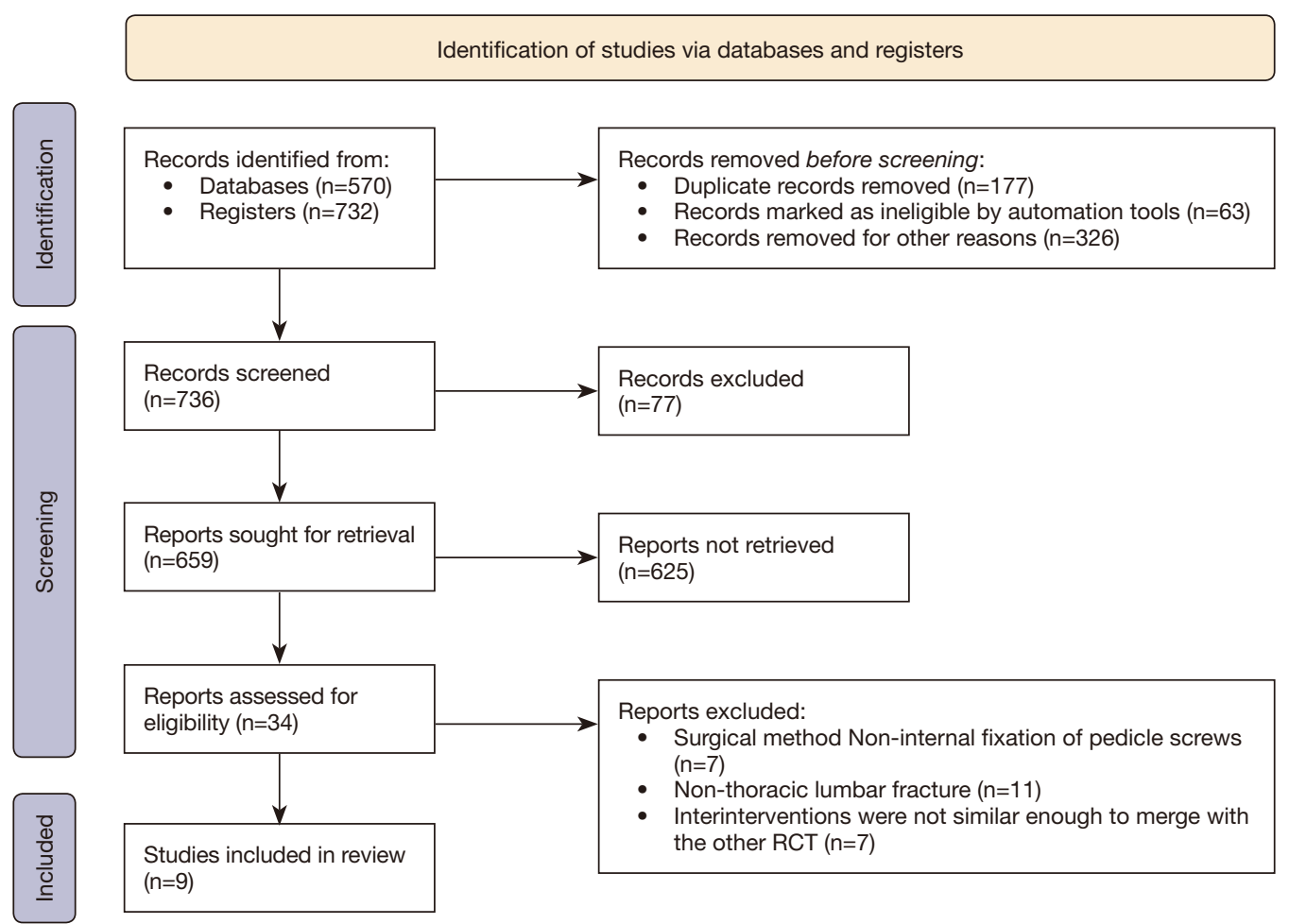

Figure 1 Retrieval flowchart of literature. RCT, randomized controlled trial.

Table 1 Basic information included in the literature

\begin{tabular}{|c|c|c|c|c|c|c|c|c|}
\hline First author & Year & Country & Type & Surgery & $\begin{array}{c}\text { The total number } \\
\text { of cases }\end{array}$ & $\begin{array}{c}\text { Follow-up } \\
\text { time (months) }\end{array}$ & $\begin{array}{l}\text { The control } \\
\text { group (case) }\end{array}$ & $\begin{array}{c}\text { The experimenta } \\
\text { group (case) }\end{array}$ \\
\hline Grass (12) & 2006 & Germany & $\begin{array}{l}\text { Observational } \\
\text { research }\end{array}$ & $\begin{array}{l}\text { Minimally invasive } \\
\text { percutaneous }\end{array}$ & 57 & 33 & 24 & 33 \\
\hline Wild (13) & 2007 & China & $\begin{array}{l}\text { Observational } \\
\text { research }\end{array}$ & $\begin{array}{l}\text { Minimally invasive } \\
\text { percutaneous }\end{array}$ & 21 & $24-60$ & 11 & 10 \\
\hline Shin (15) & 2020 & America & $\begin{array}{l}\text { Observational } \\
\text { research }\end{array}$ & $\begin{array}{l}\text { Minimally invasive } \\
\text { percutaneous }\end{array}$ & 46 & Unclear & 22 & 24 \\
\hline Grossbach (16) & 2013 & Germany & $\begin{array}{l}\text { Observational } \\
\text { research }\end{array}$ & $\begin{array}{l}\text { Minimally invasive } \\
\text { percutaneous }\end{array}$ & 39 & 16.4 & 27 & 11 \\
\hline Lee (18) & 2013 & China & $\begin{array}{l}\text { Randomized } \\
\text { controlled study }\end{array}$ & $\begin{array}{l}\text { Posterior } \\
\text { percutaneous }\end{array}$ & 59 & 50 & 27 & 32 \\
\hline Vanek (19) & 2014 & China & $\begin{array}{l}\text { Observational } \\
\text { research }\end{array}$ & $\begin{array}{l}\text { Posterior } \\
\text { percutaneous }\end{array}$ & 37 & 6 & 19 & 18 \\
\hline Yang (20) & 2019 & China & $\begin{array}{l}\text { Randomized } \\
\text { controlled study }\end{array}$ & $\begin{array}{l}\text { Posterior } \\
\text { percutaneous }\end{array}$ & 60 & 12 & 30 & 30 \\
\hline
\end{tabular}




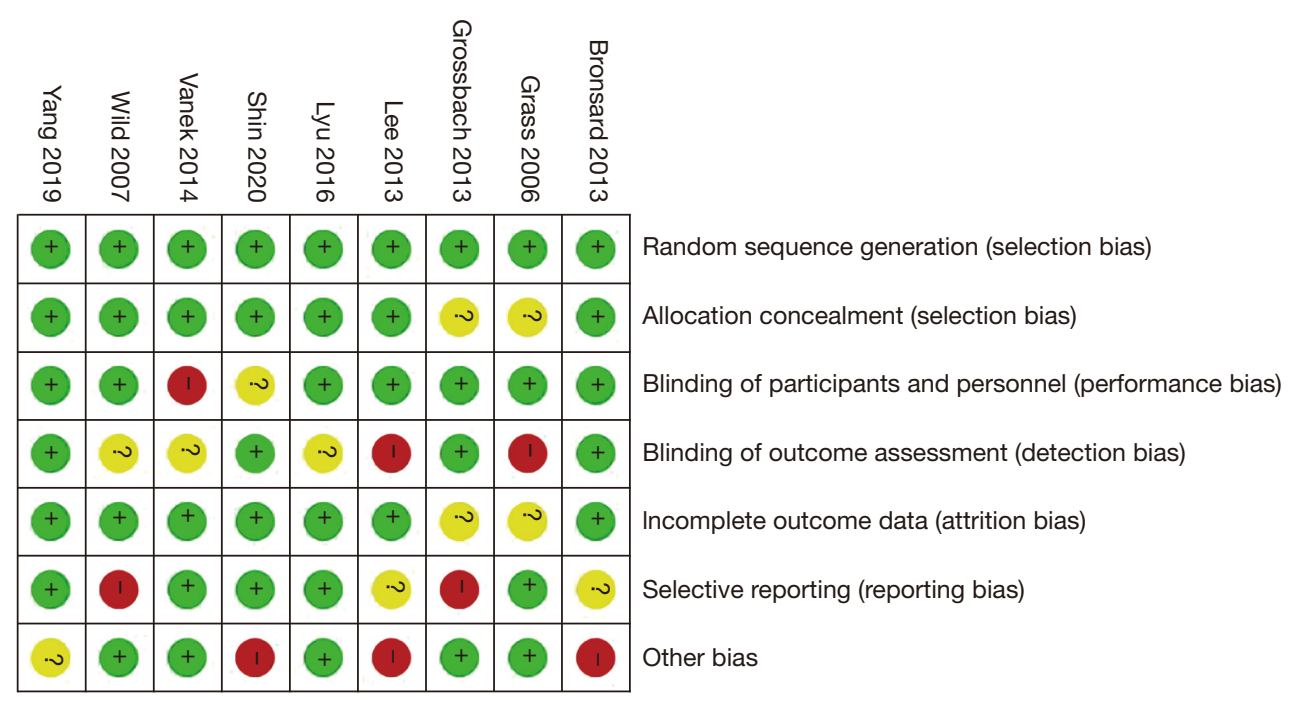

Figure 2 Bias risk assessment diagram of literature included in the study. Green dot, low risk; yellow dot, unclear; red dot, high risk.

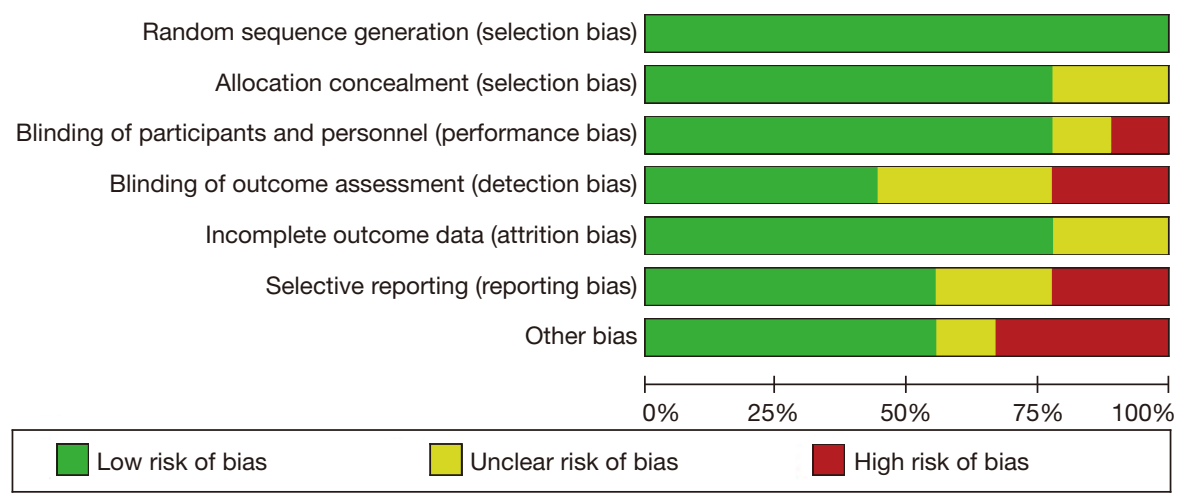

Figure 3 Bar chart showing the risk assessment of the bias of literature included in the study. The risk gradually increases from left to right, $0 \%$ means no risk of deviation, $100 \%$ means the highest risk of deviation.

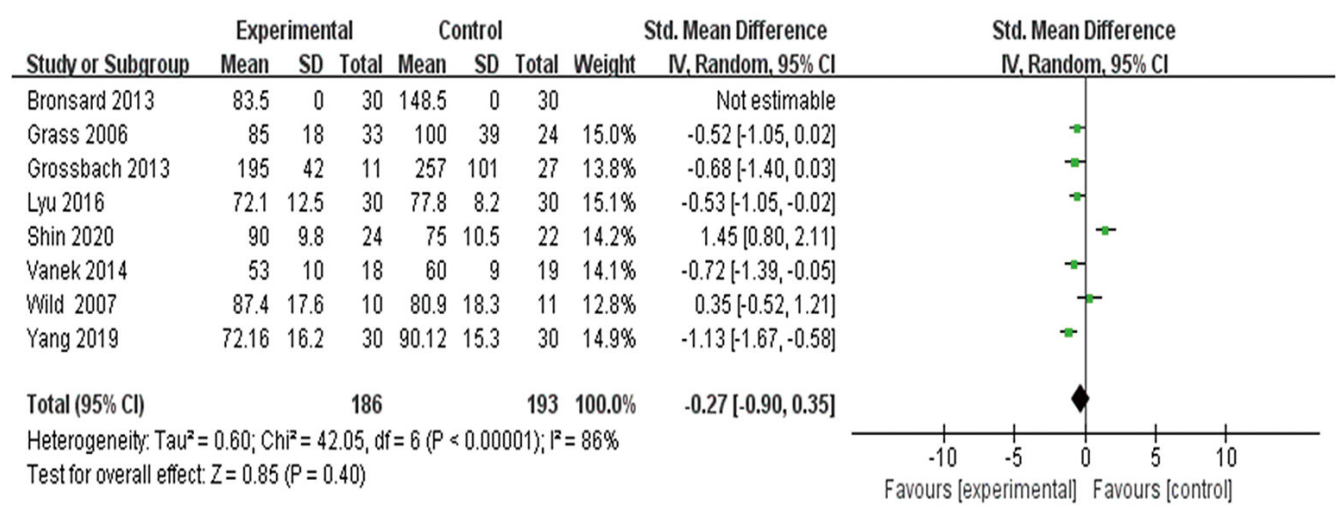

Figure 4 Forest plot showing the comparison of operation times between percutaneous pedicle screw fixation and open pedicle screw fixation. SD, standard deviation. 


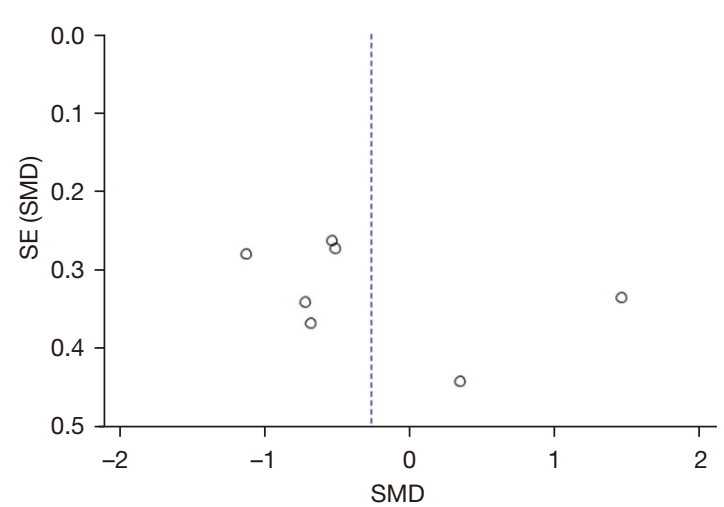

Figure 5 Funnel plot showing the comparison of operation times between percutaneous pedicle screw fixation and open pedicle screw fixation. SE, standard error; SMD, standardized mean difference.

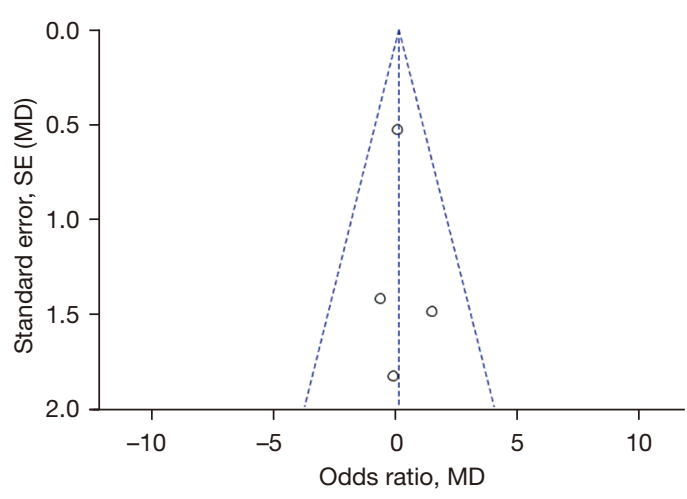

Figure 7 Funnel plot showing the degree of recovery of the cobb angle between percutaneous pedicle screw fixation and open pedicle screw fixation. SE, standard error; $\mathrm{MD}$, mean difference.

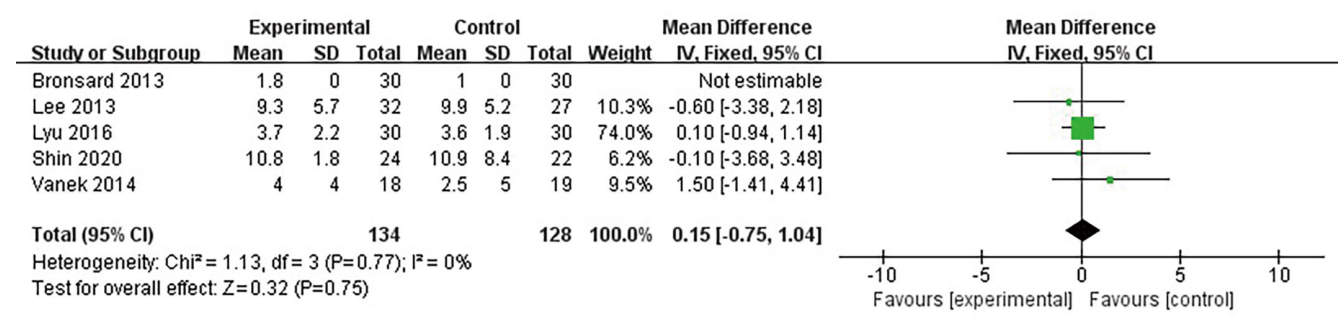

Figure 6 Forest plot showing the comparison of the cobb angle recovery between percutaneous pedicle screw fixation and open pedicle screw fixation. SD, standard deviation.

the data were on both sides of the central axis, and were symmetric in the confidence interval, which indicated that publication bias was effective.

\section{Cobb angle recovery comparison}

A total of 5 documents met the requirements and compared the use of percutaneous pedicle screw fixation and open surgery. The analysis yielded $95 \%$ CI of $0.15(-0.75,1.04)$ and $\mathrm{I}^{2}=0 \%$, which was less than $50 \%$. Therefore, the fixed effects model was used. The results in Figure 6 show that the degree of recovery of the cobb angle after percutaneous pedicle screw fixation was better than that of open pedicle screw fixation, but the difference was not significant $(\mathrm{Z}=0.32 ; \mathrm{P}=0.75)$. Figure 7 shows that the funnel plot was symmetrical, and most of the data was on both sides of the central axis, suggesting that publication bias was effective. Percutaneous pedicle screw fixation had better cobb angle recovery than open pedicle screw fixation, and the prognosis after surgery was better.

\section{Comparison of postoperative pain}

A total of 6 documents met the requirements and used percutaneous pedicle screws and posterior percutaneous pedicle screw internal fixation. The analysis showed that the $95 \%$ CI was $-0.63(-0.92,-0.34)$ and $\mathrm{I}^{2}=75 \%$, which was greater than $50 \%$, so the random effects model was selected. The results in Figure 8 show that the pain of percutaneous pedicle screw fixation was less than that of open pedicle screw fixation, and the difference was significant $(Z=4.27$; $\mathrm{P}<0.0001)$. Figure 9 shows that the funnel plot was symmetrical, and all of them presented a symmetric state within the confidence interval, indicating that there was no publication offset.

\section{Postoperative screw misalignment rate}

A total of 5 documents met the requirements and used percutaneous pedicle screws and posterior percutaneous pedicle screw internal fixation. The analysis showed that the 


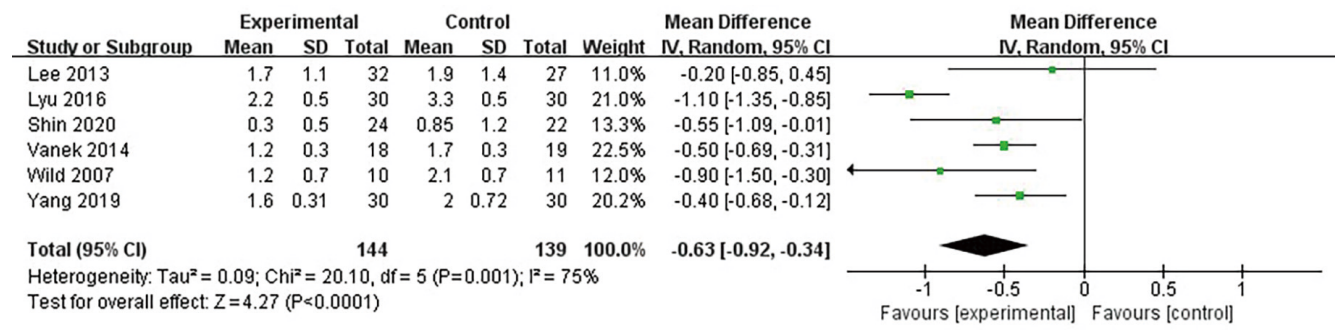

Figure 8 Forest plot of the pain between percutaneous pedicle screw fixation and open pedicle screw fixation. SD, standard deviation.

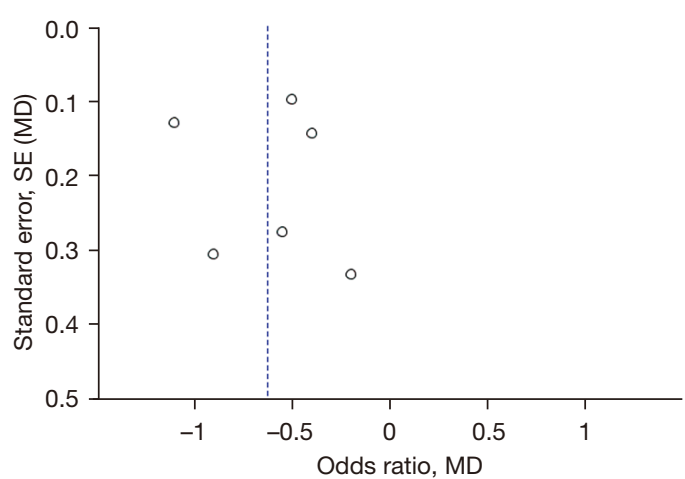

Figure 9 Funnel plot of the pain between percutaneous pedicle screw fixation and open pedicle screw fixation. SE, standard error; MD, mean difference.

$95 \%$ CI was $0.32(0.11,0.96)$ and $\mathrm{I}^{2}=0 \%$, which was less than $50 \%$. Therefore, the random effects model was used. The results in Figure 10 show that the rate of screw misalignment after percutaneous pedicle screw fixation was lower than that of open pedicle screw fixation, and the difference was significant $(\mathrm{Z}=2.04 ; \mathrm{P}=0.04)$. Figure 11 shows that the funnel plot was symmetrical, and most of the data were on both sides of the central axis, within the $95 \%$ confidence interval, which indicated that the publication bias was effective. Compared with open pedicle screw fixation, percutaneous pedicle screw fixation had a lower screw misalignment rate and fewer postoperative reoperations.

\section{Discussion}

Whether percutaneous pedicle screw surgery or traditional open pedicle screw surgery is better for the treatment of a simple thoracolumbar fracture has been controversial (21). Although percutaneous pedicle screw surgery is becoming more widely used by clinicians in the field of spinal degeneration, its role in spinal fracture or spinal injury is controversial due to the lack of detailed and valid evidence. Traditional open pedicle screw surgery has been widely used because it can adapt to various types of spinal fractures and has accurate postoperative results. However, along with the development of science, technology, and society, medicine is also making continuous progress and development. In recent decades, "minimally invasive" has become a hot topic and an emerging research direction. There is a trend in spinal fracture surgery to minimize iatrogenic injury to the soft tissue surrounding the spine. Many less invasive interventions have been proposed and used, including percutaneous vertebroplasty, percutaneous kyphoplasty, and percutaneous pedicle screw fixation (22).

The results of this meta-analysis confirmed the advantages of previously reported percutaneous pedicle screw surgery over traditional open surgery. Percutaneous pedicle screw surgery requires an incision of approximately $1 \mathrm{~cm}$ in length at each screw placement site. This incision is used to insert the needle, guide wire, and dilator tube, and the screw was screwed in with the help of the guide wire (23). The dilatation tube bluntly separates the soft tissues of the lower back and paraspinal muscles, avoiding the extensive dissection and electrosurgical burning required in open surgery. Therefore, it is of great help to reduce postoperative pain, reduce intraoperative bleeding, and improve the recovery time of patients. The amount of bleeding is closely related to the type of spinal injury such as a vertebral burst fracture, and the assessment of blood loss has always been an unsolved problem. Reducing intraoperative and postoperative blood loss also benefits postoperative recovery in elderly high-risk patients (24). The reduction in surgical trauma results in a lower incidence of surgery-related complications, and it can promote early spinal stabilization and early recovery activities and shorten hospital stays.

The included literature showed that compared with open surgery, patients with other surgical methods felt 


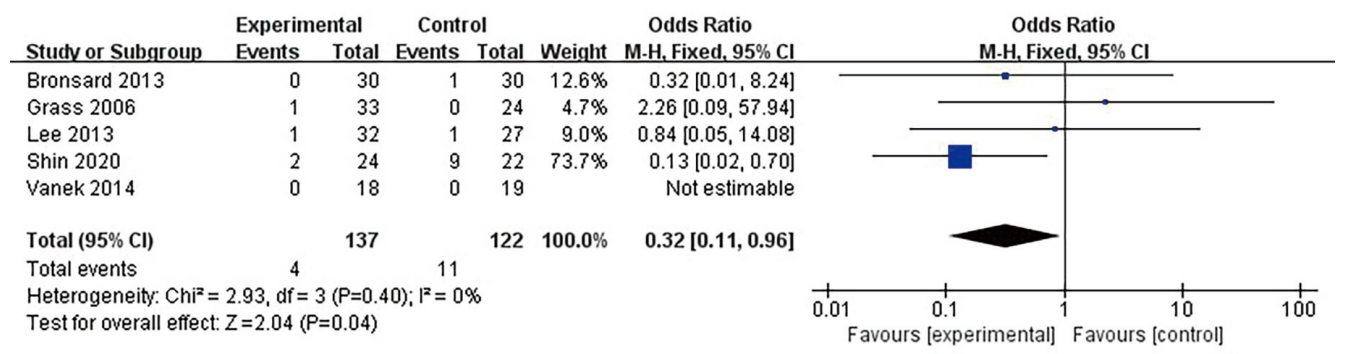

Figure 10 Forest plot showing the screw misalignment rate after percutaneous pedicle screw fixation and open pedicle screw fixation.

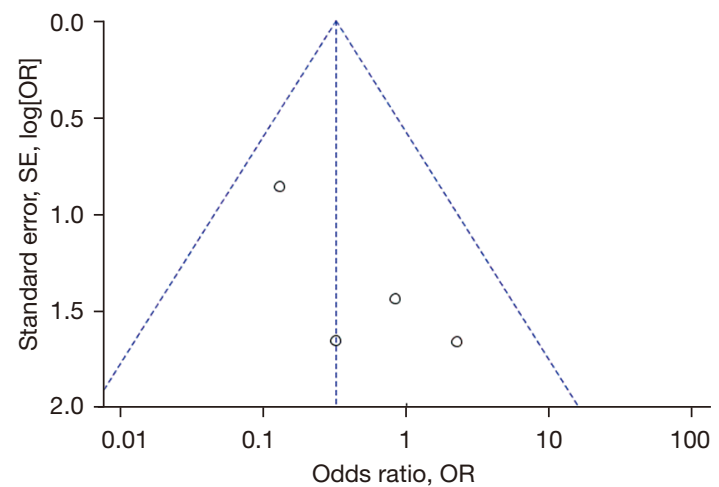

Figure 11 Funnel plot showing the screw dislocation rate after percutaneous pedicle screw fixation and open pedicle screw internal fixation. SE, standard error; OR, odds ratio.

less pain, which will become the development direction of spinal plastic surgery. However, there were also some disadvantages. First, for the safety of minimally invasive percutaneous surgery with screw insertion, the frequency of X-ray fluoroscopy increased the amount of radiation for patients and doctors and adversely affected the health of patients and doctors. The advent of computer-aided surgical navigation systems helped greatly in reducing radiation exposure, but many hospitals have yet to equip them because of their high cost. Siegel et al. [2018] (25) found that the radiation time during percutaneous pedicle screw fixation was longer than in the conventional open surgery group. The effective dose in the transcutaneous group was more than three times that in the open group. Increased radiation exposure was a hazard to patients and was a considerable injury to surgeons who performed many operations over the years. Spinal surgeons, especially those who performed minimally invasive percutaneous procedures, received higher radiation dose levels than the average orthopedic surgeon. Second, percutaneous and posterior percutaneous fixation devices were difficult to re-insert through the initial incision because the rod systems were often surrounded by tough scar tissue and the fixation device was larger. Repeated incisions can cause secondary damage. After the patient's wound has healed, reopening of the surgical wound was required if fixation was to be inserted (26). Third, limited operating experience and clinical skills can lead to damage or even fracture of the pedicle. This meta-analysis showed that, compared with traditional open surgery, other surgical methods had better surgical effects, reduced pain for the patient, and shortened operation time.

The limitations of this study are as follows. First, in the analysis of this study, the included literature was open literature and excluded unpublished gray literature. Therefore, the results derived from this study may be subject to error. Second, due to the relatively small number of cases included in this study, a large sample and multicenter randomized controlled study is still needed to evaluate the reliability of the results of this meta-analysis. Third, some postoperative efficacy indicators were not included in the study (such as postoperative vertebral height, Oswestry Disability Index (ODI) score, and postoperative clinical satisfaction of patients), resulting in incomplete data analysis.

\section{Conclusions}

A total of 9 literatures were included in this metaanalysis. Internal fixation using percutaneous and posterior percutaneous pedicle screws had a shorter operation time, lower pain, a better cobb angle recovery, and a lower postoperative screw dislocation rate and postoperative infection rate compared to open surgery. These results suggest that percutaneous pedicle screw fixation and posterior percutaneous pedicle screw fixation may be a more effective option than open surgery to treat thoracolumbar fractures. 


\section{Acknowledgments}

Funding: None.

\section{Footnote}

Reporting Checklist: The authors have completed the PRISMA reporting checklist. Available at https://apm. amegroups.com/article/view/10.21037/apm-21-3736/rc

Conflicts of Interest: All authors have completed the ICMJE uniform disclosure form (available at https://apm. amegroups.com/article/view/10.21037/apm-21-3736/coif). The authors have no conflicts of interest to declare.

Ethical Statement: The authors are accountable for all aspects of the work in ensuring that questions related to the accuracy or integrity of any part of the work are appropriately investigated and resolved.

Open Access Statement: This is an Open Access article distributed in accordance with the Creative Commons Attribution-NonCommercial-NoDerivs 4.0 International License (CC BY-NC-ND 4.0), which permits the noncommercial replication and distribution of the article with the strict proviso that no changes or edits are made and the original work is properly cited (including links to both the formal publication through the relevant DOI and the license). See: https://creativecommons.org/licenses/by-nc-nd/4.0/.

\section{References}

1. Kendler DL, Bauer DC, Davison KS, et al. Vertebral Fractures: Clinical Importance and Management. Am J Med 2016;129:221.e1-10.

2. Schousboe JT. Epidemiology of Vertebral Fractures. J Clin Densitom 2016;19:8-22.

3. Lentle B, Koromani F, Brown JP, et al. The Radiology of Osteoporotic Vertebral Fractures Revisited. J Bone Miner Res 2019;34:409-18.

4. Denis F. The three column spine and its significance in the classification of acute thoracolumbar spinal injuries. Spine (Phila Pa 1976) 1983;8:817-31.

5. Ferguson RL, Allen BL Jr. A mechanistic classification of thoracolumbar spine fractures. Clin Orthop Relat Res 1984;(189):77-88.

6. Roy-Camille R, Berteaux D, Saillant G. Unstable fractures of the spine. Surgical methods. Synthesis of the injured dorso-lumbar spine by plates screwed into vertebral pedicles. Orthop Traumatol Surg Res 2014;100:23-5.

7. Lin S, Hu J, Wan L, et al. Short-term effectiveness comparison between robotic-guided percutaneous minimally invasive pedicle screw internal fixation and traditional open internal fixation in treatment of thoracolumbar fractures. Zhongguo Xiu Fu Chong Jian Wai Ke Za Zhi 2020;34:76-82.

8. Ye H, Chen QX. Comparative study of minimally invasive percutaneous pedicle screw fixation and open surgery in the treatment of thoracolumbar fractures. Zhongguo Gu Shang 2017;30:105-9.

9. Defino HLA, Costa HRT, Nunes AA, et al. Open versus minimally invasive percutaneous surgery for surgical treatment of thoracolumbar spine fractures- a multicenter randomized controlled trial: study protocol. BMC Musculoskelet Disord 2019;20:397.

10. Lang Z, Tian W, Liu Y, et al. Minimally Invasive Pedicle Screw Fixation Using Intraoperative 3-dimensional Fluoroscopy-based Navigation (CAMISS Technique) for Hangman Fracture. Spine (Phila Pa 1976) 2016;41:39-45.

11. Huang $\mathrm{P}$, Wang $\mathrm{Y}, \mathrm{Xu} \mathrm{J}$, et al. Minimally invasive unilateral pedicle screws and a translaminar facet screw fixation and interbody fusion for treatment of singlesegment lower lumbar vertebral disease: surgical technique and preliminary clinical results. J Orthop Surg Res 2017;12:117.

12. Grass R, Biewener A, Dickopf A, et al. Percutaneous dorsal versus open instrumentation for fractures of the thoracolumbar border. A comparative, prospective study. Unfallchirurg 2006;109:297-305.

13. Wild MH, Glees M, Plieschnegger C, et al. Five-year follow-up examination after purely minimally invasive posterior stabilization of thoracolumbar fractures: a comparison of minimally invasive percutaneously and conventionally open treated patients. Arch Orthop Trauma Surg 2007;127:335-43.

14. Bronsard N, Boli T, Challali M, et al. Comparison between percutaneous and traditional fixation of lumbar spine fracture: intraoperative radiation exposure levels and outcomes. Orthop Traumatol Surg Res 2013;99:162-8.

15. Shin SR, Lee SS, Kim JH, et al. Thoracolumbar burst fractures in patients with neurological deficit: Anterior approach versus posterior percutaneous fixation with laminotomy. J Clin Neurosci 2020;75:11-8.

16. Grossbach AJ, Dahdaleh NS, Abel TJ, et al. Flexiondistraction injuries of the thoracolumbar spine: open fusion versus percutaneous pedicle screw fixation. Neurosurg 
Focus 2013;35:E2.

17. Lyu J, Chen K, Tang Z, et al. A comparison of three different surgical procedures in the treatment of type A thoracolumbar fractures: a randomized controlled trial. Int Orthop 2016;40:1233-8.

18. Lee JK, Jang JW, Kim TW, et al. Percutaneous shortsegment pedicle screw placement without fusion in the treatment of thoracolumbar burst fractures: is it effective?: comparative study with open short-segment pedicle screw fixation with posterolateral fusion. Acta Neurochir (Wien) 2013;155:2305-12; discussion 2312.

19. Vanek P, Bradac O, Konopkova R, et al. Treatment of thoracolumbar trauma by short-segment percutaneous transpedicular screw instrumentation: prospective comparative study with a minimum 2-year follow-up. J Neurosurg Spine 2014;20:150-6.

20. Yang M, Zhao Q, Hao D, et al. Comparison of clinical results between novel percutaneous pedicle screw and traditional open pedicle screw fixation for thoracolumbar fractures without neurological deficit. Int Orthop 2019;43:1749-54.

21. Leveque JC. Commentary: Minimally Invasive Pedicle Screw Fixation With Indirect Decompression by

Cite this article as: $\mathrm{Lu} \mathrm{J}$, Chen Y, Hu M, Sun C. Systematic review and meta-analysis of the effect of using percutaneous pedicle screw internal fixation for thoracolumbar fractures. Ann Palliat Med 2022;11(1):250-259. doi: 10.21037/apm-21-3736
Ligamentotaxis in Pathological Fractures. Oper Neurosurg (Hagerstown) 2020;19:E140-1.

22. Coric D, Rossi VJ, Peloza J, et al. Percutaneous, Navigated Minimally Invasive Posterior Cervical Pedicle Screw Fixation. Int J Spine Surg 2020;14:S14-21.

23. Zhou ZZ, Wang YM, Liang X, et al. Minimally Invasive Pedicle Screw Fixation Combined with Percutaneous Kyphoplasty Under O-Arm Navigation for the Treatment of Metastatic Spinal Tumors with Posterior Wall Destruction. Orthop Surg 2020;12:1131-9.

24. Fischer S, Vogl TJ, Kresing M, et al. Minimally invasive screw fixation of fractures in the thoracic spine: CTcontrolled pre-surgical guidewire implantation in routine clinical practice. Clin Radiol 2016;71:997-1004.

25. Siegel GW, Biermann JS, Calinescu AA, et al. Surgical Approach to Bone Metastases. Curr Osteoporos Rep 2018;16:512-8.

26. Hamad A, Vachtsevanos L, Cattell A, et al. Minimally invasive spinal surgery for the management of symptomatic spinal metastasis. Br J Neurosurg 2017;31:526-30.

(English Language Editor: C. Mullens) 